\title{
Epigallocatechin-3-Gallate Suppresses the Expression of TNF- $\alpha$-Induced MMP-1 via MAPK/ERK Signaling Pathways in Human Dermal Fibroblasts
}

\author{
Hea-Ryeoun Won, ${ }^{a}$ Pyeongjae Lee, ${ }^{b}$ Sol-ra Oh, ${ }^{a}$ and Yong-Min Kim*,a \\ ${ }^{a}$ School of Cosmetic Science and Beauty Biotechnology, Semyung University; 65 Semyung-ro, Jecheon, \\ Chungcheongbuk-do 27136, Korea: and ${ }^{b}$ School of Industrial Bio-pharmaceutical Science, Semyung University; 65 \\ Semyung-ro, Jecheon, Chungcheongbuk-do 27136, Korea.
}

Received March 31, 2020; accepted September 14, 2020

Deeper wrinkles and loss of elasticity are one of the skin-aging symptoms. Collagen breakdown by matrix metalloproteinase-1 (MMP-1), which is induced by reactive oxygen species (ROS) and pro-inflammatory cytokines, has been known to be responsible for these skin-aging symptoms. Therefore, much attention has been paid to chemicals to suppress the MMP-1 activity. Epigallocatechin-3-gallate (EGCG), catechin rich in green tea, has been reported to show antioxidant and protect skin from various stimuli such as UV and chemicals. In this study, we evaluated the inhibitory effect of EGCG on MMP-1 gene expression and secretion in tumor necrosis factor- $\alpha$ (TNF- $\alpha$ )-treated human dermal fibroblast cells (Hs68 cells). Pre-treatment with EGCG (10 and $20 \mu \mathrm{M})$ suppressed TNF- $\alpha$-induced MMP-1 expression and secretion. EGCG also reduced the phosphorylation of extracellular signal regulated kinase (ERK) significantly but not that of p38 activation and c-Jun N-terminal kinase (JNK). Besides, EGCG (10 and $20 \mu \mathrm{M})$ showed the inhibitory effect on mitogen-activated protein extracellular kinase (MEK) and Src phosphorylation which is reported to be upstream signal proteins of ERK signal pathway. Based on these results, EGCG might have potential activity to slow down the skin-aging through inhibition of collagen breakdown, which remains to be elucidated.

Key words epigallocatechin-3-gallate; anti-aging; matrix metalloproteinase-1; skin fibroblast

\section{INTRODUCTION}

Recently, the prevention of skin-aging has become a popular interest worldwide. Skin-aging is one of the most frequently observed skin symptoms and its causes can be classified as intrinsic, such as aging, and extrinsic environmental factors, such as UV rays and stress. ${ }^{1)}$ Therefore, skin anti-aging methods focusing on the improvement of wrinkles and elasticity and the regeneration of the extracellular matrix (ECM) have received attention. ECM is distributed throughout all tissues and organs, and it is called the extracellular matrix as there are no cells. ECM plays a role in protecting the cells from external forces by forming physical structures as well as by establishing fundamentals of cellular development via biochemical signal transmission. ECM is composed of water, proteins, and polysaccharides. Collagen is the main component of ECM and it is the main substrate protein produced by the skin fibroblasts. The dermis contains a large amount of collagen. The main role of collagen is known for the mechanical rigidity, the resistance of the connective tissues and cohesiveness of the tissues, support for the cellular adhesion, and for inducing cell division. Therefore, the ECM collagen breakdown is related to various skin aging. ${ }^{2)}$ Matrix metalloproteinase 1 (MMP-1), which is a fibroblast collagenase that breaks down collagen, is a component of the MMP family. Increased MMP-1 within ECM induces collagen fiber degradation, and broken-down collagen fragments are further degraded by MMP-3 and MMP-9. ${ }^{3)}$ As the amount of collagen decreases, wrinkles deepen and elasticity is reduced, causing skin sagging and rough skin surface, which are the main causes of skin aging. MMP-1 expression and secretion in skin fibroblasts increase as a result of UV ray exposure, directly, and also interleukin 1-beta (IL-1 $\beta$ ) and tumor necrosis factor- $\alpha$ (TNF- $\alpha$ ) that are secreted from keratinocytes exposed to UV rays, indirectly. ${ }^{4,5)}$ Increased MMP-1 from the above causes will induce rapid skin aging. As a result, experimental models targeting UV rays to discover cosmetic substances that suppress skin aging or models confirming MMP-1 expression and secretion in fibroblasts treated with inflammatory cytokines are used. Many substances have demonstrated suppressed skin aging through this models. ${ }^{6-8)}$ Epigallocatechin-3-gallate (EGCG, Fig. 1A) is an important component of polyphenol in green tea, and it is well known for its anti-cancer, antiinflammatory, and antioxidant effects. ${ }^{9,10)}$ In skins, EGCG has been reported for its antiaging effects by suppressing MMP increase induced by fine dust, heat shock, and UVB. ${ }^{1-13)}$ However, there have been no reports of MMP-1 suppression in dermal fibroblasts stimulated by TNF- $\alpha$. In this study, EGCG effects in suppressing MMP-1 expression and secretion in fibroblasts stimulated by TNF- $\alpha$ have been demonstrated.

\section{MATERIALS AND METHODS}

Materials Epigallocatechin-3-gallate (EGCG) and human tumor necrosis factor- $\alpha$ were purchased from Sigma-Aldrich (St. Louis, MO, U.S.A.). The antibodies (phosphorylated extracellular signal regulated kinase (p-ERK), ERK, p-c-Jun N-terminal kinase (JNK), JNK, p-p38, p38, Akt, p-Akt, Src, $\mathrm{p}$-Src, mitogen-activated protein extracellular kinase (MEK), p-MEK, and $\beta$-actin) were purchased from Cell Signaling Technology (Danvers, MA, U.S.A.). Human skin fibroblast Hs68 cells were obtained from American Type Culture Col- 
A<smiles>O=C(O[C@H]1Cc2c(O)cc(O)cc2O[C@H]1c1cc(O)c(O)c(O)c1)c1cc(O)c(O)c(O)c1</smiles>

C

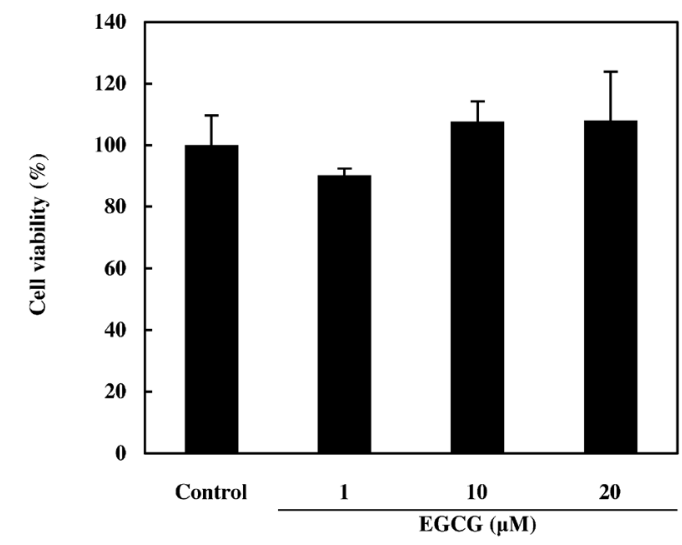

$\mathbf{E}$

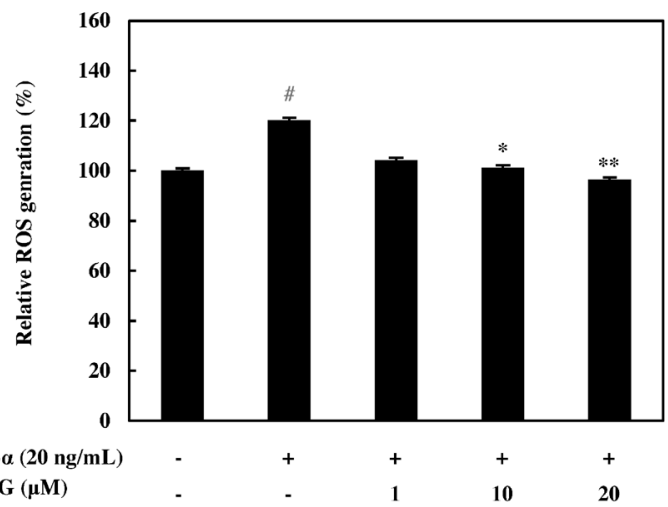

B

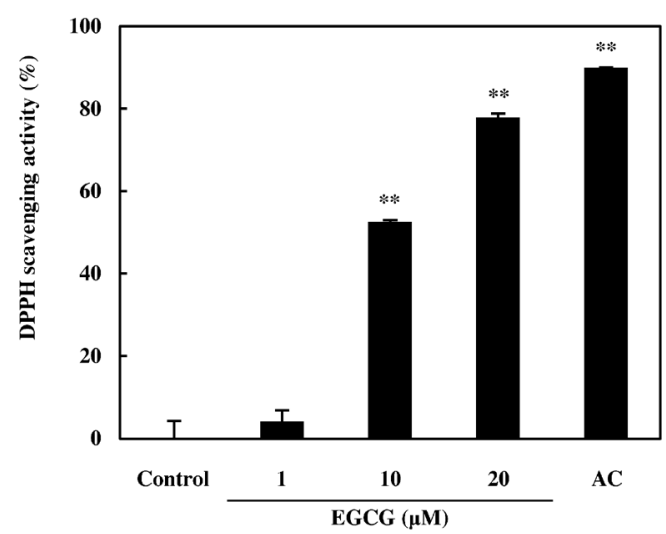

D
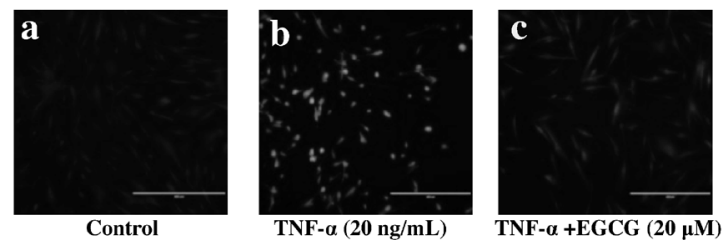

Fig. 1. The Effects of EGCG $(1-20 \mu \mathrm{M})$ on Cell Viability and the Anti-oxidant Effect of EGCG in Hs68 Cells

(A) Chemical structure of EGCG. (B) DPPH radical scavenging activity of EGCG. Ascorbic acid (AC) was positive control. (C) Cytotoxicity of EGCG in Hs68 cells. (D and, E) Effect of EGCG on intracellular ROS accumulation in Hs68 cells. The scale bar is $400 \mu$ m. Cells were incubated with 1,10 , and $20 \mu \mathrm{M}$ of EGCG for $24 \mathrm{~h}$. Cell viability was measured using MTT assay. $\# p<0.05$ compared with the vehicle control; ${ }^{*} p<0.05$ compared with the control; ${ }^{* *} p<0.01$ compared with the control.

lection (ATC C, Manassas, VA, U.S.A.).

Cell Culture Cells were grown in Dulbecco's modified Eagle medium (DMEM) complemented $10 \%$ fetal bovine serum (FBS) and $1 \%$ penicillin-streptomycin at $37^{\circ} \mathrm{C}$ in $5 \%$ $\mathrm{CO}_{2}$ incubator.

Cell Viability Cell viability was assessed using a 3-(4,5-dimethylthiazol-2-yl)-2,5-diphenyltetrazolium bromide (MTT) assay. Cells were treated with EGCG at concentrations ranging from 1,10 , and $20 \mu \mathrm{M}$ for $24 \mathrm{~h}$. And then, MTT solution $(5 \mathrm{mg} / \mathrm{mL})$ was added and cells were incubated at $37^{\circ} \mathrm{C}$ in $5 \% \mathrm{CO}_{2}$ for $3 \mathrm{~h}$. The supernatant was then removed, and $100 \mu \mathrm{L}$ of dimethyl sulfoxide (DMSO) was added. Finally, absorbance was measured on a microplate reader at $570 \mathrm{~nm}$. The level of cell viability was expressed as \% compared with the control group.
2,2-Diphenyl-1-picrylhydrazyl (DPPH) The DPPH radical scavenging ability of EGCG was measured by the slightly modified previous method. ${ }^{14)}$ Samples were dissolved in a solution of $99 \%$ methanol (Honey well, U.S.A.) and distilled water at a ratio of $1: 1$ at 0 (control), 1,10 and $20 \mu \mathrm{M}$. Then $2 \mathrm{~mL}$ of $0.2 \mathrm{mM}$ DPPH in EtOH was added to $100 \mu \mathrm{L}$ sample solution. Then absorbance at $517 \mathrm{~nm}$ was measured after $20 \mathrm{~min}$ of incubation at $25^{\circ} \mathrm{C}$. In the study, ascorbic acid $250 \mu \mathrm{M}$ was used as a positive control. The inhibition of DPPH radicals by the samples was calculated according to the following equation:

$$
[1-(\text { Absorbance of sample/Absorbance of control) }] \times 100
$$

Detection of Reactive Oxygen Species (ROS) Production The production of ROS by Hs68 cells was measured using the 2,7-dichlorofluorescein diacetate (DCF-DA) dye method. 
A

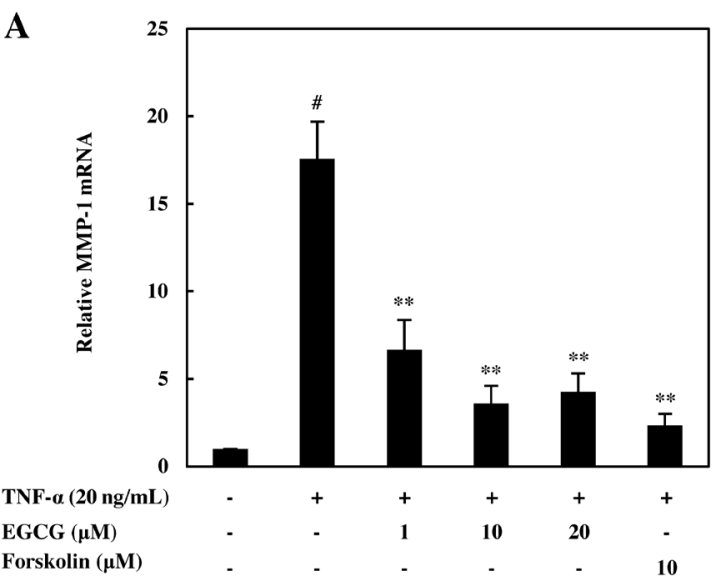

B

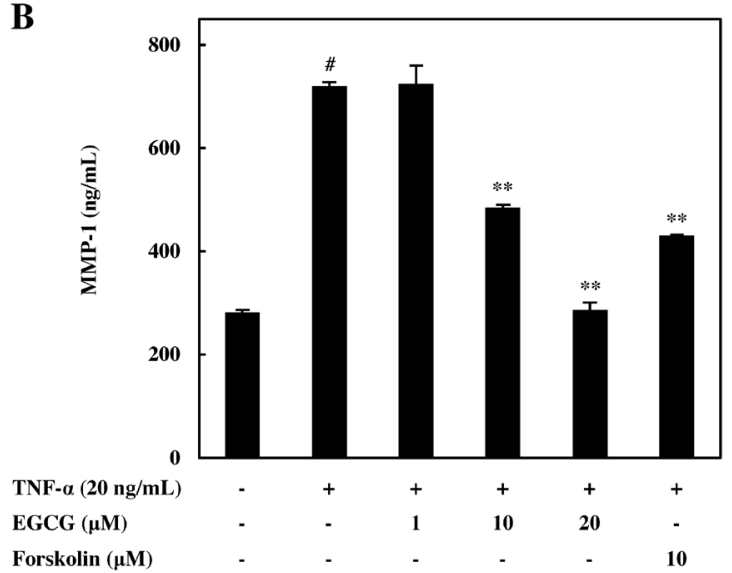

Fig. 2. The Effects of EGCG on the mRNA Expression and Secretion of MMP-1 in TNF- $\alpha$-Induced Hs68 Cells

(A) EGCG inhibits TNF- $\alpha$-induced MMP-1 mRNA expression. (B) EGCG inhibits TNF- $\alpha$-induced MMP-1 secretion. Hs68 cells were pre-treated with EGCG (1-20 $\mu$ M) for $45 \mathrm{~min}$, and then stimulated with TNF- $\alpha(20 \mathrm{ng} / \mathrm{mL})$ for $15 \mathrm{~min}$. Forskolin was positive control. \#p<0.05 compared with the vehicle control; $* p<0.05$ compared with the TNF- $\alpha$. ** $p<0.01$ compared with the TNF- $\alpha$.

The Hs68 cells were pretreatment with EGCG $(1-20 \mu \mathrm{M})$ for $45 \mathrm{~min}$ prior to the induction with TNF- $\alpha(20 \mathrm{ng} / \mathrm{mL})$ for $24 \mathrm{~h}$. After removal of the supernatant, cells were treated with $10 \mu \mathrm{M}$ DCF-DA in the dark for $45 \mathrm{~min}$ and then washed twice with phosphate buffered saline (PBS). The DCFDA-stained cells were monitored and visualized under the fluorescence microscope using an EVOS fl digital inverted fluorescence microscope (AMG). To quantify the ROS level, cells were seeded on a 6 well plate and treated as described above. Relative fluorescence intensities were measured using a fluorescence spectrophotometer at excitation and emission wavelengths of 485 and $530 \mathrm{~nm}$, respectively. The levels of intracellular ROS were expression as \% compared with the control group.

Enzyme-Linked Immunosorbent Assay (ELISA) MMP-1 secretion was measured by MMP-1 Human ELISA kit (GE healthcare Life Sciences; little Chalfont, Buckinghamshire, U.K.) following the manufacturer's instructions. The Hs68 cells were pretreatment with EGCG $(1-20 \mu \mathrm{M})$ for $45 \mathrm{~min}$ prior to the induction with TNF- $\alpha(20 \mathrm{ng} / \mathrm{mL})$ for $24 \mathrm{~h}$. Then the cell supernatant was collected.

Quantitative Real-Time PCR (qRT-PCR) The Hs68 cells were pretreatment with EGCG $(1-20 \mu \mathrm{M})$ for $45 \mathrm{~min}$ prior to the induction with TNF- $\alpha(20 \mathrm{ng} / \mathrm{mL})$ for $24 \mathrm{~h}$. Then the cell supernatant was discarded and washed with PBS. Total RNA was extracted from cell lysates using TRIzol reagent (Ambion, U.S.A.), and cDNA was prepared using a Revertra ACE- $\alpha$ - (Toyobo, Japan), according to the manufacturer's instructions. Quantification of mRNA by qRT-PCR was carried out using Taqman RT-PCR Master Mix. The cDNA was amplified by using the following primers are MMP-1 (Hs00899658_m1), glyceraldehyde-3-phosphate dehydrogenase (GAPDH) (Hs02786624_g1).

Western Blot Analysis The Hs68 cells were pretreatment with EGCG $(1-20 \mu \mathrm{M})$ for $45 \mathrm{~min}$ prior to the induction with TNF- $\alpha(20 \mathrm{ng} / \mathrm{mL})$ for $15 \mathrm{~min}$ except for the determination of mitogen-activated protein kinases (MAPKs). Then, the cell supernatant was discarded and washed with PBS. The cells were lysed with pre-prep (lysis buffer) including protease and phosphatase inhibitor. Insoluble debris was removed by centrifugation at $12000 \mathrm{rpm}$ for $20 \mathrm{~min}$, and protein con- tent was determined using bicinchoninic acid (BCA) assay. Equal amounts of protein were separated by sodium dodecyl sulfate-polyacrylamide gel electrophoresis (SDS-PAGE) and transferred to polyvinylidene difluoride (PVDF) membranes. The membranes were incubated with primary antibodies at $4{ }^{\circ} \mathrm{C}$ overnight, then washed with TBST $(1 \times$ Tris-buffered saline (TBS) including $0.1 \%$ Tween-20), exposed to secondary antibodies for $2 \mathrm{~h}$ at room temperature. The membranes were washed 3 times and the protein bands were visualized by the enhanced and quantified using Image $J$ software from the NIH (Bethesda, MD, U.S.A.).

Statistical Analysis The SPSS 12.0 version (SPSS Inc., Chicago, IL, U.S.A.) was applied for statistical analysis. Each experiment was done in triplicate and the data are represented as the mean \pm standard error of the mean. Statistical analysis of the data was performed using Student's $t$-test. Differences with a $p<0.05$ were considered statistically significant.

\section{RESULTS}

Effect of EGCG on the ROS Production Induced by TNF- $\alpha$ in Hs68 Cells Antioxidant effects of EGCG were measured, as there have been reports of increased cellular ROS production with TNF- $\alpha$ treatment and that ROS affects MMP family protein expression. ${ }^{15,16)}$

A direct effect of EGCG in radical scavenging was confirmed through DPPH radical. When treated with EGCG 1, 10, and $20 \mu \mathrm{M}$, DPPH radical elimination rates were 4.2, 52.5, and $77.9 \%$, respectively, suggesting increased radical elimination with increased EGCG concentration (Fig. 1B). In order to determine whether EGCG suppresses cellular ROS production, the effect of EGCG on cell survival was tested. The results suggested that 1,10 , and $20 \mu \mathrm{M}$ of EGCG did not affect cell survival (Fig. 1C). When fibroblast was treated with TNF- $\alpha$ alone, ROS production was confirmed using DCF-DA fluorescence, which was reduced when treated with EGCG $20 \mu \mathrm{M}$ (Figs. 1D, E).

Inhibitory Effect of EGCG on MMP-1 mRNA Expression and Secretion in TNF- $\alpha$-Stimulated Hs68 Dermal Fibroblast Effects of EGCG on suppressing MMP-1 gene expression and secretion were confirmed using TNF- $\alpha$ treated 
A

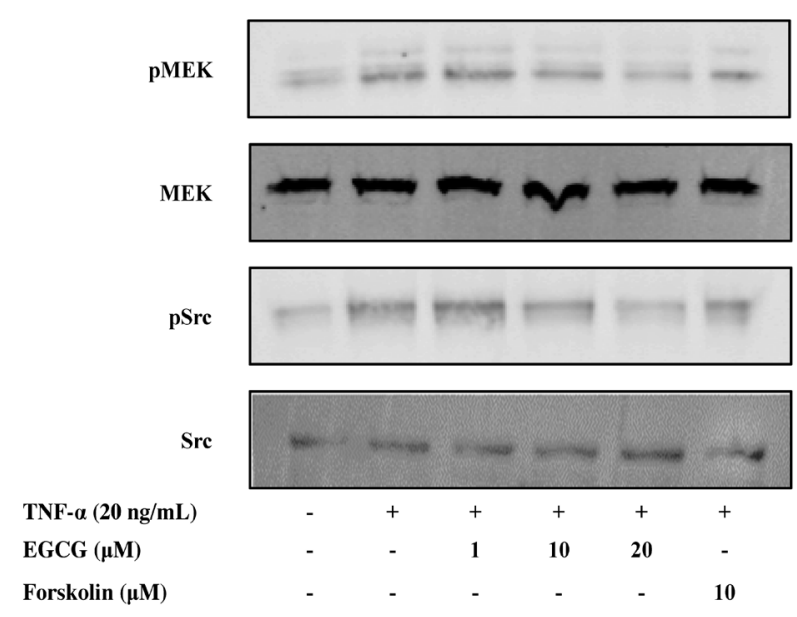

$\mathrm{C}$

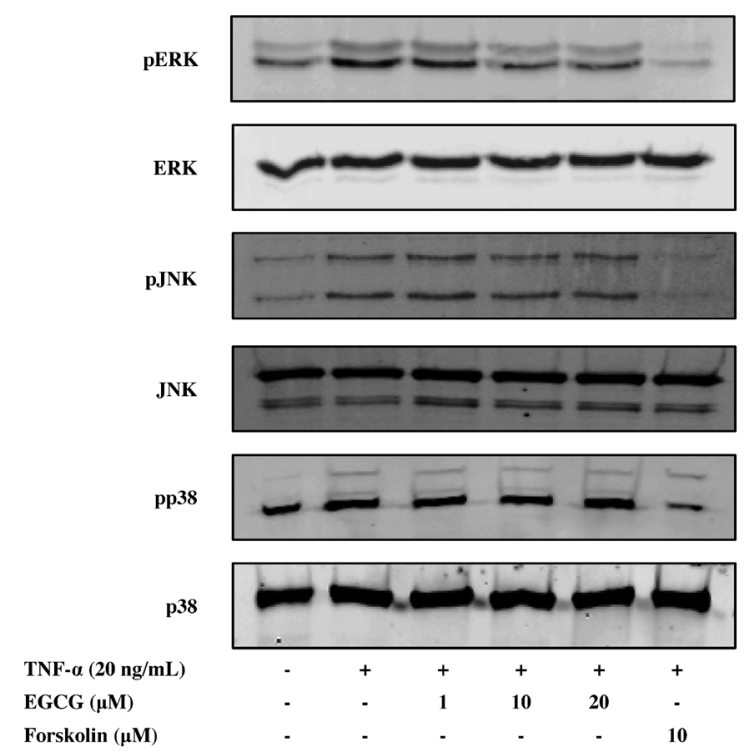

B
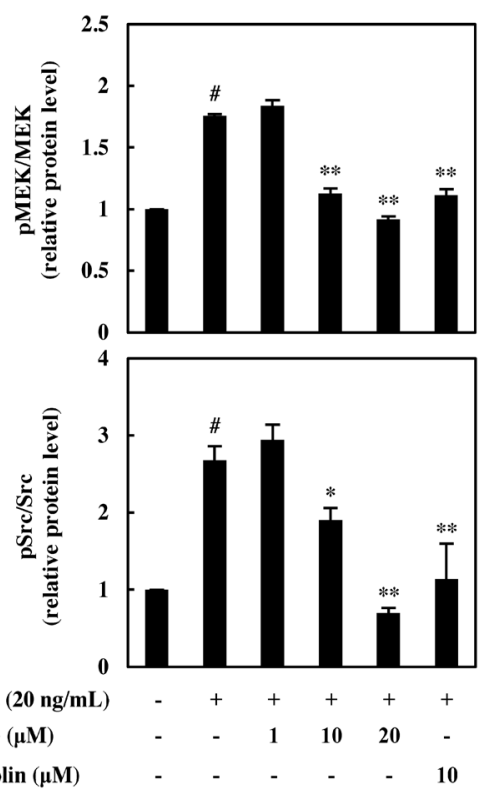

$\mathrm{D}$
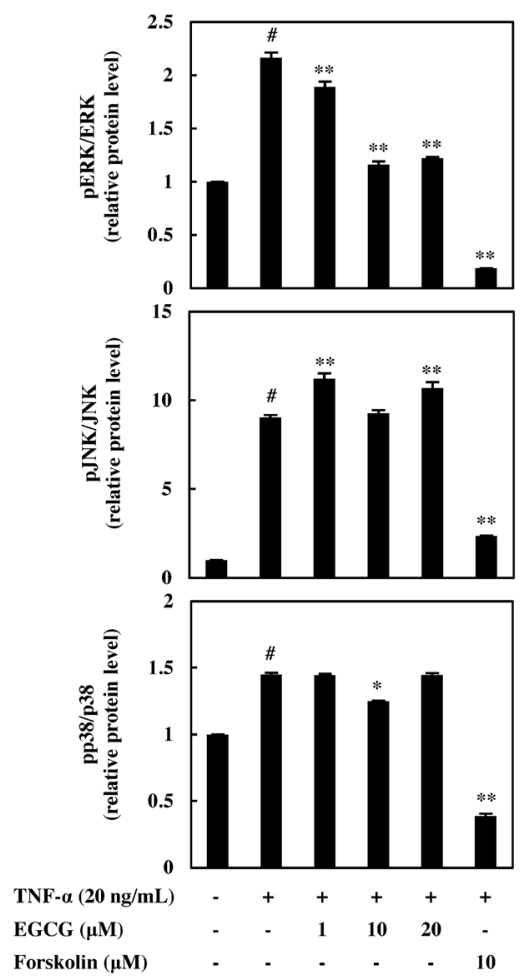

Fig. 3. The Effects of EGCG on ERK Signaling Pathway

Respective western blots presenting the effects of EGCG on phosphorylation of (A and, B) ERK, JNK and p38. (C and, D) The effects of EGCG on phosphorylation of Src and MEK. Inhibitory effect of EGCG on MMP-1 secretion through extracellular signal-regulated kinase MMP-1 was secreted through extracellular signal-regulated kinase (ERK) inactivation in TNF- $\alpha$ stimulated Hs68 cells. Hs68 cells were pre-treated with EGCG (1-20 $\mu \mathrm{M})$ for $45 \mathrm{~min}$, and then stimulated with TNF- $\alpha$ (20 ng/mL) for $15 \mathrm{~min}$. Forskolin was positive control. $\# p<0.05$ compared with the vehicle control; $* p<0.05$ compared with the TNF- $\alpha$; $* *<<0.01$ compared with the TNF- $\alpha$.

Hs68 cells. Hs68 cells were treated with EGCG $(1,10,20 \mu \mathrm{M})$ and TNF- $\alpha(20 \mathrm{ng} / \mathrm{mL})$ was added after $45 \mathrm{~min}$. After $24 \mathrm{~h}$, MMP-1 quantity and intracellular mRNA expression were measured from the supernatant with ELISA and qRT-PCR. When treated with TNF- $\alpha$ alone, MMP-1 quantity in the supernatant was 2.5 times greater. When treated with EGCG, increased MMP-1 quantity in the supernatant was reduced dose-dependently, and EGCG treatment at $20 \mu \mathrm{M}$ reduced the quantity similar to that in supernatant for cells not treated with TNF- $\alpha$. Forskolin, a positive control known to reduce MMP-1, was used at $10 \mu \mathrm{M}$ and it also reduced MMP-1 quantity (Fig. 2A). In order to identify the effects of EGCG on increased MMP-1 expression in fibroblast in response to TNF- $\alpha$, MMP-1 mRNA expression was measured using qRT-PCR. When treated with TNF- $\alpha$ only, the expression increased by 17.5 times compared to the control, as expected. When treated with EGCG 1, 10, and $20 \mu \mathrm{M}$, MMP-1 mRNA expressions increased only by $6.7,3.6$, and 4.2 times, respectively, which 
A

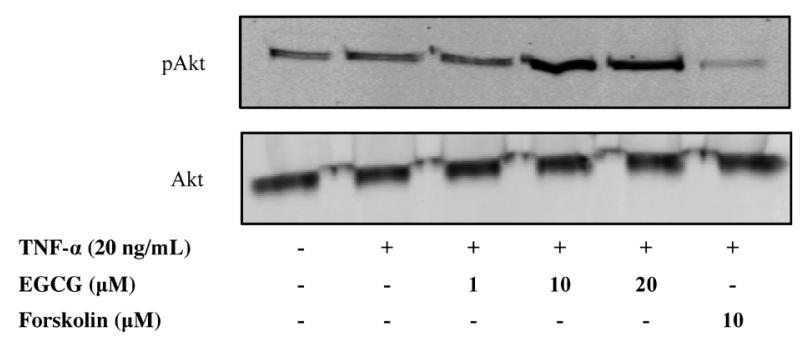

B

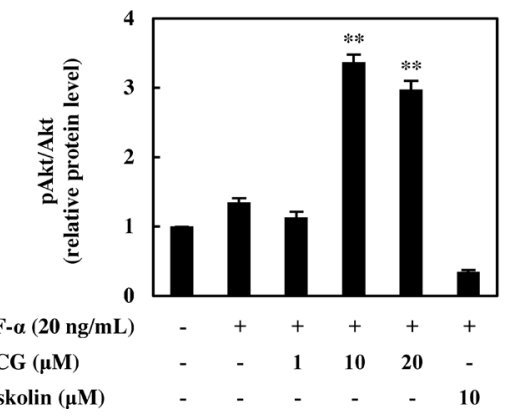

Fig. 4. EGCG Upregulates Akt Phosphorylation

Hs68 cells were pre-treated with EGCG $(1-20 \mu \mathrm{M})$ for $45 \mathrm{~min}$, and then stimulated with TNF- $\alpha(20 \mathrm{ng} / \mathrm{mL})$ for $15 \mathrm{~min}$. Forskolin was positive control. \# $p<0.05$ compared with the vehicle control; ${ }^{*} p<0.05$ compared with the TNF- $\alpha .{ }^{*} p<0.01$ compared with the control

were greatly reduced compared to when treated with TNF- $\alpha$ only (Fig. 2B). There have been reports of forskolin, which increases cAMP by activating adenylyl cyclase, in suppressing MMP-1 expression in TNF- $\alpha$-stimulated fibroblast. Therefore, it was used as a positive control. ${ }^{17)}$ In this study, forskolin suppressed MMP-1 mRNA expression that was increased in response to TNF- $\alpha$ as well (Fig. 2B).

Inhibitory Effect of EGCG on Src-Dependent ERK Signaling Pathway The effects of EGCG on the activation of MAPK in Hs68 cells stimulated with TNF- $\alpha$ were investigated, as there have been reports of MAPK important role in MMP-1 gene expression and secretion. EGCG $(1,10$, and $20 \mu \mathrm{M})$ was treated $45 \mathrm{~min}$ before TNF- $\alpha(20 \mathrm{ng} / \mathrm{mL})$ treatment, which was treated for $15 \mathrm{~min}$. EGCG dose-dependently suppressed ERK phosphorylation but did not affect the phosphorylation of JNK and p38 (Figs. 3A, B). These results suggest that EGCG suppresses TNF- $\alpha$-induced ERK signaling pathway and therefore affects MMP-1 expression and secretion. For this reason, MEK and Src phosphorylation, which are upstream signaling pathways of ERK, were investigated, and it was found that MEK and Src phosphorylation increased after TNF- $\alpha$ treatment but EGCG 10 and $20 \mu \mathrm{M}$ treatments suppressed their phosphorylation (Figs. 3C, D).

Effect of EGCG on Phosphorylation of Akt There have been reports of 7,8-Dihydroxyflavone and Compound $\mathrm{K}$, which are known to suppress TNF- $\alpha$-induced MMP-1 increase in fibroblast, suppressing Akt activation. Therefore, the effects of Akt on phosphorylation were investigated. ${ }^{6,7)}$ In this study, there was no increase in Akt phosphorylation as a result of TNF- $\alpha$ treatment. Interestingly, Akt phosphorylation after EGCG 10 and $20 \mu \mathrm{M}$ treatments increase by approximately 3 times, compared to the control group, and the positive control suppressed Akt phosphorylation to a great extent (Figs. 4A, B).

\section{DISCUSSION}

Collagen is the main component of ECM and it contributes to the elasticity of the skin. Collagen exists in the dermis in a great amount. As it has a close relationship with skin wrinkles, collagen deficiency can induce skin wrinkles. MMP-1 is an important enzyme in collagen breakdown, and it is a known cause of wrinkle formation by increasing collagen breakdown in the dermis. Therefore, substances that suppress the increase of MMP-1 expression or secretion in fibroblasts have gained attention as a cosmetic material. There are sev- eral reasons that increase MMP-1 expression and secretion in fibroblasts. UVA and heat are direct causes while cytokines are indirect causes. ${ }^{4,5,12}$ Keratinocytes of epidermis exposed to UVB are known to secrete inflammatory cytokines, including TNF- $\alpha$, which stimulate epidermal fibroblasts, thus increasing ROS and MMP-1 expression and secretion. There are also reports of ROS playing a role in MMP-1 expression as well as increased ROS production in response to TNF- $\alpha$ stimulation. Since there may be an association between increased MMP-1 and ROS in response to TNF- $\alpha$, suppressive effects of EGCG on ROS production was first investigated. In this study, it was found that EGCG has a direct effect on radical elimination using DPPH assay. Existing studies report $\mathrm{IC}_{50}$ of $13 \mu \mathrm{M}$ for $\mathrm{DPPH}$ elimination with EGCG, suggesting that the results of the current study are similar to previous results. ${ }^{18)}$ It was found that EGCG suppressed ROS production in fibroblasts treated with TNF- $\alpha$. EGCG has been reported to suppress ROS production in damaged brain tissues. ${ }^{19)}$ Antioxidant effects of EGCG may involve direct elimination of radicals, but there are also reports that EGCG increases the expression of enzymes that resist oxidative stress in various cell types. Therefore, the effects of EGCG by increasing antioxidant enzymes in dermal fibroblast may not be excluded. $^{20,21)}$ EGCG effects on MMP-1 in response to TNF- $\alpha$ was measured by quantifying MMP-1 and mRNA expression in the supernatant using ELISA and qRT-PCR. Interestingly, EGCG 1,10 , and $20 \mu \mathrm{M}$ treatments clearly suppressed mRNA production. But MMP-1 amount in the supernatant that was decreased dose-dependently at EGCG 10 and $20 \mu \mathrm{M}$ was not observed at $1 \mu \mathrm{M}$. The effects of TNF- $\alpha$ on MMP- 1 of dermal fibroblast can be classified as increased activation of MMP-1 transcription factors and increased extracellular secretion. In this study, EGCG appears to suppress the activation of transcription factors that participate in MMP-1 gene expression at low concentrations, but higher concentrations may be required to suppress signaling pathways that play a role in secretion. Moreover, in order to ECM remodeling to occur, increased extracellular MMP-1 activation is required and it is thought that signaling pathways that intensity secretion plays more role than increased MMP-1 expression in fibroblasts, but more studies are needed to confirm this. MAPK is a well-known signaling protein to participate in MMP-1 expression and secretion. $^{22,23)}$

ERK, in particular, increases MMP-1 activation by enhancing AP-1 activation, and $\mathrm{p} 38$ has been reported to increase MMP-1 mRNA stability. ${ }^{24)}$ Effects of EGCG on MAPK phos- 
phorylation in response to TNF- $\alpha$ were investigated, which showed suppressed ERK phosphorylation but not suppression of JNK and p38 phosphorylation. Phosphorylation of MEK, which is an upstream signaling protein of ERK, was measured and similar results as ERK phosphorylation were shown. This indicates that EGCG may partially interrupt the MEK-ERK signaling pathway. There have been reports of Compound $\mathrm{K}$, found in ginseng, suppresses MMP-1 secretion and Src phosphorylation in dermal fibroblasts treated with TNF- $\alpha$, therefore Src phosphorylation after EGCG was measured.') At EGCG $20 \mu \mathrm{M}$, Src phosphorylation was greatly suppressed but phosphorylation increased at $1 \mu \mathrm{M}$ and it was greater than when treated with TNF- $\alpha$ alone. More studies will be needed but it can be considered that the effects of EGCG on Src phosphorylation in response to TNF- $\alpha$ may vary based on the dose. As previously shown, EGCG at $1 \mu \mathrm{M}$ suppressed MMP-1 mRNA expression but without changes in MMP-1 quantity in the supernatant may be related to Src phosphorylation.

There are studies reporting conflicting results of the effects of Akt on MMP-1 expression and secretion. 7,8-Dihydroxyflavone and Compound $\mathrm{K}$ are reported to suppress increased MMP-1 expression and secretion in response to TNF- $\alpha$ and phosphorylation of $\mathrm{Akt},{ }^{6,7)}$ but there are also reports of suppressed Akt activation increasing the expression and secretion of MMP-1. ${ }^{25,26)}$ The effects of IL-13 in suppressing MMP-1 in $\mathrm{TNF}-\alpha$ treated fibroblasts are reversed when treated with Akt suppressants. $^{27)}$

In this study, EGCG at 10 and $20 \mu \mathrm{M}$ improved Akt phosphorylation. Forskolin, which was used as a positive control for suppressed MMP-1 expression and secretion, suppressed Akt phosphorylation. This suggests that the direction of MMP-1 expression and secretion pathway cannot be estimated with Akt phosphorylation alone, and various signaling proteins for MMP-1 expression and secretion are related to Akt phosphorylation. Taken all together, EGCG suppressed MMP-1 production and secretion, in response to the pro-inflammatory cytokine TNF- $\alpha$, in fibroblasts and can be used as an anti-aging substance for the skin. However, further studies will be conducted as more reports are needed for understanding the effects of different EGCG concentrations on phosphorylation of signaling proteins and Akt activation.

Conflict of Interest The authors declare no conflict of interest.

Supplementary Materials The online version of this article contains supplementary materials.

\section{REFERENCES}

1) Baumann L. Skin ageing and its treatment. J. Pathol., 211, 241-251 (2007).

2) Quan T, Fisher GJ. Role of age-associated alterations of the dermal extracellular matrix microenvironment in human skin aging: a mini-review. Gerontology, 61, 427-434 (2015).

3) Yoshizaki N, Fujii T, Hashizume R, Masaki H. A polymethoxyflavone mixture, extracted from orange peels, suppresses the UVBinduced expression of MMP-1. Exp. Dermatol., 25 (Suppl. 3), 52-56 (2016).

4) Jian J, Pelle E, Yang Q, Pernodet N, Maes D, Huang X. Iron sensitizes keratinocytes and fibroblasts to UVA-mediated matrix metalloproteinase-1 through TNF- $\alpha$ and ERK activation. Exp. Dermatol.,
20, 249-254 (2011).

5) Honda A, Abe R, Makino $T$, Norisugi O, Fujita $Y$, Watanabe $H$, Nishihira J, Iwakura Y, Yamagishi S, Shimizu H, Shimizu T. Interleukin- $\beta$ and macrophage migration inhibitory factor (MIF) in dermal fibroblasts mediate UVA-induced matrix metalloproteinase-1 expression. J. Dermatol. Sci., 49, 63-72 (2008).

6) Choi JW, Lee J, Park YI. 7,8-Dihydroxyflavone attenuates TNF- $\alpha$ induced skin aging in Hs68 human dermal fibroblast cells via down-regulation of the MAPKs/AKT signaling pathways. Biomed. Pharmacother., 95, 1580-1587 (2017).

7) Lee CS, Bae IH, Han J, Choi GY, Hwang KH, Kim DH, Yeom MH, Park YH, Park M. Compound K inhibits MMP-1 expression through suppression of c-src-dependent ERK activation in TNF- $\alpha$ stimulated dermal fibroblast. Exp. Dermatol., 23, 819-824 (2014).

8) Moon HJ, Lee SR, Shim SN, Jeong SH, Stonik VA, Rasskazov VA, Zvyagintseva T, Lee YH. Fucoidan inhibits UVB-induced MMP-1 expression in human skin fibroblasts. Biol. Pharm. Bull., 31, 284289 (2008).

9) Tauber AL, Schweiker SS, Levonis SM. From tea to treatment; epigallocatechin gallate and its potential involvement in minimizing the metabolic changes in cancer. Nutr. Res., 74, 23-36 (2020).

10) Ohishi $T$, Goto S, Monira P, Isemura M, Nakamura Y. Anti-inflammatory action of green tea. Antiinflamm. Antiallergy Agents Med. Chem., 15, 74-90 (2016).

11) Wang L, Lee WW, Cui YR, Ahn G, Jeon YJ. Protective effect of green tea catechin against urban fine dust particle-induced skin aging by regulation of NF-kB, AP-1, and MAPKs signaling pathways. Environ. Pollut., 252 (Pt. B), 1318-1324 (2019).

12) Kim JE, Shin MH, Chung JH. Epigallocatechin-3-gallate prevents heat shock-induced MMP-1 expression by inhibiting AP-1 activity in human dermal fibroblasts. Arch. Dermatol. Res., 305, 595-602 (2013).

13) Bae JY, Choi JS, Choi YJ, Shin SY, Kang SW, Han SJ, Kang YH. (-)Epigallocatechin gallate hampers collagen destruction and collagenase activation in ultraviolet-B-irradiated human dermal fibroblasts: involvement of mitogen-activated protein kinase. Food Chem. Toxicol., 46, 1298-1307 (2008).

14) Yang B, Zhao M, Shi J, Yang N, Jiang Y. Effect of ultrasonic treatment on the recovery and DPPH radical scavenging activity of polysaccharides from longan fruit pericarp. Food Chem., 106, 685-690 (2008).

15) Meier B, Radeke HH, Selle S, Younes M, Sies H, Resch K, Habermehl GG. Human fibroblasts release reactive oxygen species in response to interleukin-1 or tumour necrosis factor- $\alpha$. Biochem. J., 263, 539-545 (1989).

16) Polte T, Tyrrell RM. Involvement of lipid peroxidation and organic peroxides in UVA-induced matrix metalloproteinase-1 expression. Free Radic. Biol. Med., 36, 1566-1574 (2004).

17) Park CH, Moon Y, Shin CM, Chung JH. Cyclic AMP suppresses matrix metalloproteinase-1 expression through inhibition of MAPK and GSK-3 $\beta$. J. Invest. Dermatol., 130, 2049-2056 (2010).

18) Kim E, Hwang K, Lee J, Han SY, Kim EM, Park J, Cho JY. Skin protective effect of epigallocatechin gallate. Int. J. Mol. Sci., 19, 173 (2018).

19) Qin S, Chen M, Fang W, Tan X, Xie L, Yang Y, Qin T, Li N. Cerebral protection of epigallocatechin gallate (EGCG) via preservation of mitochondrial function and ERK inhibition in a rat resuscitation model. Drug Des. Devel. Ther., 13, 2759-2768 (2019).

20) Gao Z, Han Y, Hu Y, Wu X, Wang Y, Zhang X, Fu J, Zou X, Zhang J, Chen X, Jose PA, Lu X, Zeng C. Targeting HO-1 by epigallocatechin-3-gallate reduces contrast-induced renal injury via anti-oxidative stress and anti-inflammation pathways. PLOS ONE, 11, e0149032 (2016).

21) Cheng-Chung Wei J, Huang HC, Chen WJ, Huang $\mathrm{CN}$, Peng $\mathrm{CH}$, Lin CL. Epigallocatechin gallate attenuates amyloid $\beta$-induced inflammation and neurotoxicity in EOC 13.31 microglia. Eur. J. 
Pharmacol., 770, 16-24 (2016).

22) Brauchle M, Glück D, Di Padova F, Han J, Gram H. Independent role of $\mathrm{p} 38$ ERK1/2 mitogen-activated kinases in the upregulation of matrix metalloproteinase-1. Exp. Cell Res., 258, 135-144 (2000).

23) Park S, Jung HH, Park YH, Ahn JS, Im YH. ERK/MAPK pathways play critical roles in EGFR ligand-induced MMP1 expression. Biochem. Biophys. Res. Commun., 407, 680-686 (2011).

24) Reunanen N, Li SP, Ahonen M, Foschi M, Han J, Kahari VM. Activation of $\mathrm{p} 38 \alpha$ MAPK enhances collagenase-1 (matrix metalloproteinase (MMP)-1) and stromelysin-1 (MMP-3) expression by mRNA stabilization. J. Biol. Chem., 277, 32360-32368 (2002).

25) Bujor AM, Pannu J, Bu S, Smith EA, Muise-Helmericks RC, Tro- janowska M. Akt blockade downregulates collagen and upregulates MMP1 in human dermal fibroblasts. J. Invest. Dermatol., 128, 1906-1914 (2008).

26) Bujor AM, Nakerakanti S, Morris E, Hant FN, Trojanowska M. Akt inhibition up-regulates MMP1 through a CCN2-dependent pathway in human dermal fibroblasts. Exp. Dermatol., 19, 347-354 (2010).

27) Brown Lobbins ML, Shivakumar BR, Postlethwaite AE, Hasty KA. Chronic exposure of interleukin-13 suppress the induction of matrix metalloproteinase-1 by tumour necrosis factor $\alpha$ in normal and scleroderma dermal fibroblasts through protein kinase B/Akt. Clin. Exp. Immunol., 191, 84-95 (2018). 